\title{
Clinical Risk Factors Associated with HIV-Tuberculosis Co-Infection Among Patients on Antiretroviral Therapy, Bungoma and Webuye County Hospitals (2015), Kenya
}

\author{
Robert Shihuzire Magomere ${ }^{1}$, Ronald Omenge Obwoge ${ }^{2, *}$ \\ ${ }^{1}$ County Coordinating Tuberculosis and Leprosy Services, Bungoma, Kenya \\ ${ }^{2}$ Department of Community Health, Faculty of Health Sciences, Egerton University, Nakuru, Kenya \\ Email address: \\ robertmagomere@yahoo.com (R. S. Magomere), Obwogeo@yahoo.com (R. O. Obwoge) \\ *Corresponding author
}

\section{To cite this article:}

Robert Shihuzire Magomere, Ronald Omenge Obwoge. Clinical Risk Factors Associated with HIV-Tuberculosis Co-Infection Among Patients on Antiretroviral Therapy, Bungoma and Webuye County Hospitals (2015), Kenya. European Journal of Preventive Medicine. Vol. 6, No. 4, 2018, pp. 38-44. doi: 10.11648/j.ejpm.20180604.11

Received: August 25, 2017; Accepted: September 7, 2017; Published: September 19, 2018

\begin{abstract}
Tuberculosis (TB) is the leading causes of death among people living with Human Immune Deficiency Virus (HIV) and first presenting sign in majority of people living with HIV. Factors influencing TB among HIV patients on anti retroviral treatment (ART) are not well described in our settings. The study aimed to assess clinical factors influencing occurrence of TB among people living with HIV after ART initiation in Bungoma and Webuye hospitals in Bungoma County. The study population consists of 156 cases and 156 controls. Case control study conducted from January $2017-$ April 2017 in two public hospitals in Bungoma County. Cases were adult people living with HIV who developed TB after ART initiation and controls were adult people living with HIV who did not develop TB after ART initiation. An interviewer administered structured questionnaire was used to collect information. at 95\% CI and variables with p-value of $<0.05$ at multivariable logistic regression were considered as significant predictors of the outcome variable. The findings of the study were presented in text and tables. The result of this study shows that after adjusting for potential confounders not being on Isonazid (adjusted odd ratio $[\mathrm{AOR}]=35.97,95 \%$ confidence interval $[\mathrm{CI}] 13.81,90.20)$, ), having World Health Organization (WHO) clinical stage III/IV (AOR = 15.53; 95\% CI: 7.67, 31.47), having interrupted ART (AOR=2.72; 95\%CI: 0.35,21.31), were predictors for increase risk of TB in PLWH after ART initiation. Not smoking (AOR=0.31;95\%CI:0.13,0.71) had decreases chances of acquiring TB in PLWH after ART initiation. In this study, increasing coverage of isoniazid preventive therapy reduced risk of TB among HIV patients. Study recommends that all PLWH should be screened for TB, but for patients who have advanced disease condition (WHO clinical stage III/IV) intensified screening is highly recommended during treatment follow up.
\end{abstract}

Keywords: Antiretroviral Therapy, Co-Infection, Clinical Characteristics

\section{Introduction}

Tuberculosis (TB) is the leading causes of death among people living with Human immune deficiency virus (HIV) which shares about $25 \%$ of all causes of the deaths [1]. HIV weakens the immune system and makes them more susceptible for TB infection. On the other hand, TB increases the progression of HIV to acquired immune deficiency syndrome (AIDS) stage [2]. TB is among the first presenting sign in the majority of AIDS patients; it is also the most common presenting illness among people living with HIV, including those who are taking Antiretroviral Treatment (ART) [3].

In 2014, 9.6 million people had acquired tuberculosis of which 1.2 million people were HIV positive. Out of the global TB-HIV co-infection, 74\% (888,000 cases) was from Sub-Saharan Africa [4]. Kenya, a low-middle income country is ranked $15^{\text {th }}$ among the 22 TB high burden countries [4]. In Kenya, of all the cases notified for TB, 31\% are TB-HIV co-infected [5].

The life time risk of developing active TB in HIV-negative individuals is approximately $10 \%$, while the lifetime risk 
approaches 50\% among HIV positive [6]. It is estimated that about one-third of people with HIV are also infected with TB [7]. Even though ART is known to decrease incidence of TB, but some studies have reported TB incidence in HIV patients on ART [8-9].

In developing countries incidence of TB occurrence has been associated with factors like socio-economic [10], lifestyle/habits [11], clinical [10-11], laboratory [10] and other co-morbidities, eg, diabetes [12]. Many patients either have a history of TB when they start ART, or they develop TB while receiving ART in the developing world [13]. It has not been well delineated what factors influence the development of TB in patients on ART [14]. In sub-Saharan Africa, the incidence of tuberculosis in adults receiving highly active antiretroviral therapy (HAART) is higher than in HIV negative adults [15]. Studies on risk factors of TB were done in the general population but determinants of active TB among HIV patients are not well described in our settings.

Understanding the Clinical risk factors of active TB over time in patients on ART is crucial for the design of effective preventive strategies. This study aimed to assess Clinical Risk Factors associated with HIV-Tuberculosis Co-Infection among Patients enrolled on Antiretroviral Therapy, Bungoma and Webuye County Hospitals in the year 2015.

\section{Methodology}

\subsection{Study Setting}

This study was conducted in two public hospital found in Bungoma county which is locate about $420 \mathrm{~km}$ from Nairobi the capital city of Kenya. The two public health facilities are providing free ART services. Bungoma County is located in the western region of Kenya and is one of the 47 counties in Kenya. It is 2,069 square kilometers and has a population of about 1.6 million, with $52.9 \%$ of the population living below the poverty line. Agriculture is the main economic activity [16]. It is divided into 10 sub-counties namely Bumula, Mt Elgon, Kabuchai, Kanduyi, Kimilili, Sirisia, Tongaren, Cheptais, Webuye East and Webuye west.

This study was conducted between January 2017, and April 2017.

\subsection{Participants}

The design for this study was unmatched case control, ratio of 1: 1. Cases were TB/HIV co-infected patients whereas controls were non TB infected HIV-positive patients who had already enrolled on ART.

The inclusion criteria for the study were being 15 years and above, TB/HIV co-infected (PTB, EPTB, mixed or disseminated) and on ART for cases and PLHIV with nonTB infected on ART were selected for controls. Those patients who were unable to give consent, transferred to other facilities outside of the study area, and not confirmed as TB were excluded from the study.

To select the study subjects, lists of cases and controls were prepared using unique identification numbers from records found in ART clinics by computer-generated random numbers. Cases and controls were selected proportional to a number of patients on clinical care in the health facilities during the study period. With the procedure, 156 TB coinfected and 156 non-TB infected HIV positives were selected for cases and controls, respectively.

\subsection{Measurements}

Being tuberculosis co-infected or not co-infected was the dependent variable for the study. The independent variables include socio demographic and economic characteristics (age, sex, income, educational status, and marital status), host and clinical related characteristics (WHO clinical stage, CD4 count, past history of TB, body mass index (BMI), smoking, history of asthma, and diabetic mellitus), and environmental related characteristics (overcrowding, wall and floor type of residential house).

\subsection{Data Collection}

Four trained nurse counselors ( 2 per each facility) were used to collect data through face to face interview approach. Pretested structured questionnaire was used to collect the data. The interview was made in a separate room to ensure privacy and to facilitate discussions between the interviewer and the respondent. Other clinical characteristics data were retrieved from each patient record. The overall data collection process was supervised by the investigator and co investigator.

\subsection{Data Analysis}

Analysis was made using statistical package for social science (SPSS) version 20.0 software package. Descriptive statistics were used to assess normality, outliers and identify missing values. Bivariate analysis was performed to see the association between the dependent and independent variables. Multivariable logistic regression was done by entering all variables with $P$ value less than 0.05 in the bivariate analysis.

\subsection{Ethical Approval}

This study was reviewed and approved by AMREF research and ethics committee (approval number P254-2016). Permission was granted from the county director of health. A verbal consent was obtained from all study participants 18 years and above, for those under 18years consent was obtain from the guardian.

\section{Study Results}

\subsection{Socio Demographic Characteristics}

A total of 312 (156 cases and 156 controls) were selected and interviewed in the study. The response rate was $100 \%$. More than half $192(53.8 \%)$ of them were females. The median age was $37.6(\mathrm{IQR}=8)$ years. The mean age was 37 
(SD10.59). Males were 93 (60\%) for cases and women for controls were 109 (70\%). The Males cases were 3 time more likely to develop TB [odds ratio (OR) $=3.495 \%$ confidence interval (CI): 2.14, 5.47)] compared to female cases. The Gender was significantly associated with development of TB $(\mathrm{p}<0.05)$. The ages between 55 and 64 were $78 \%$ less likely to develop TB than those in age bracket $15-24$ (OR $=0.129$; 95\% CI: 0.10, 1.13). Being widower/divorced was three times more likely to develop $\mathrm{TB}(\mathrm{OR}=2.03$; 95\% CI: 0.99 , 4.12). Marital status was significantly associated with development of TB $(\mathrm{p}=<0.001)$. Those cases with primary and non education level were three times more likely to develop TB compared to those with tertiary education $(\mathrm{OR}=$ 3.16; 95\%CI: 1.53, 6.45). Level of education was significantly associated with development of TB $(p=0.002)$. (As shown in table 1).

Table 1. Socio-demographic characteristics of study participants in factors affecting TB HIV co-infection in Bungoma County, 2015.

\begin{tabular}{|c|c|c|c|c|c|c|c|c|c|}
\hline & \multirow{2}{*}{$\begin{array}{l}\text { Cases } \\
n=156(\%)\end{array}$} & \multirow{2}{*}{$\begin{array}{l}\text { Controls } \\
n=156(\%)\end{array}$} & \multirow{2}{*}{ P value } & \multirow{2}{*}{ uOR } & \multicolumn{2}{|c|}{$95 \%$ CI } & \multirow{2}{*}{ AOR } & \multicolumn{2}{|c|}{$95 \%$ CI } \\
\hline & & & & & Lower & Upper & & Lower & Upper \\
\hline \multicolumn{10}{|l|}{ Gender } \\
\hline Males & 93 (59.6.) & $47(30.1)$ & $<0.001$ & 3.42 & 2.14 & 5.47 & 3.33 & 1.80 & 6.15 \\
\hline Females & $63(39.4)$ & $109(69.9)$ & & 1 & & & & & \\
\hline \multicolumn{10}{|l|}{ Age } \\
\hline $15-24$ & $20(12.8)$ & $12(8)$ & 0.002 & 1 & & & & & \\
\hline $25-34$ & $35(22)$ & $64(41)$ & & 0.686 & 0.221 & 2.134 & .313 & .129 & .762 \\
\hline $45-54$ & $27(17)$ & $31(20)$ & & 0.559 & 0.213 & 1.469 & .456 & .169 & 1.233 \\
\hline $55-64$ & $17(11)$ & $7(4)$ & & 0.359 & 0.129 & 0.995 & 1.130 & .319 & 4.006 \\
\hline \multicolumn{10}{|l|}{ Marital status } \\
\hline single & $28(18)$ & $22(14)$ & $<0.001$ & 1 & & & & & \\
\hline married & $61(39)$ & $108(69)$ & & 0.444 & 0.234 & 0.842 & .295 & .138 & .632 \\
\hline Divorced/ widow & $67(43)$ & $26(17)$ & & 2.025 & 0.987 & 4.155 & 1.194 & .496 & 2.874 \\
\hline \multicolumn{10}{|l|}{ Level of education } \\
\hline Secondary & $33(21)$ & $49(31)$ & & 1.502 & 0.682 & 3.307 & 1.690 & .725 & 3.937 \\
\hline Tertiary & $13(8)$ & $29(19)$ & & 1 & & & 1.000 & & \\
\hline \multicolumn{10}{|l|}{ Level of income } \\
\hline Ksh 0- 5000 & $115(73)$ & $98(63)$ & 0.567 & & & & & & \\
\hline Ksh. 6000-10000 & $17(11)$ & $33(21)$ & & & & & & & \\
\hline ksh. 11000-15000 & $10(6)$ & $6(4)$ & & & & & & & \\
\hline$>15000$ & $14(9)$ & $16(10)$ & & & & & & & \\
\hline
\end{tabular}

\subsection{Clinical Factors Associated}

The study performed a Bivariate and Multivariable logistic regression analysis on various clinical factors. The result indicates those cases in WHO clinical stage iii and iv were 15 times more likely to develop TB compared to those in stage $\mathrm{i}$ \&ii \% $(\mathrm{OR}=15.63 ; 95 \% \mathrm{CI}: 8.99-27.16)$. The results showed that WHO clinical stage was significantly associated with development of TB $(\mathrm{p}=<0.001)$. The results indicate that CD4 cell of below 500 was 12 times more likely to develop TB compared to those with CD4 500 and above (OR=12.14; 95\%CI: 5.03, 29.33). The results indicate that CD4 was significantly associated with development of TB $(p<0.001)$. The result showed that body mass index (BMI) less than 18.5 was six times more likely to develop TB compared to those with BMI 18.5 and above $(\mathrm{OR}=6.32 ; 95 \% \mathrm{CI}$ : 3.78, 10.58). The results indicate that BMI was not significantly associated with development of TB $(p=0.212)$. The results indicate that cases who had interrupted ART were five times more likely to develop TB compared to those who did not interrupt the ART $(\mathrm{OR}=5.57 ; 95 \% \mathrm{CI}: 3.14,9.9)$, interruption of ART was significantly associated with development of TB $(p=<0.001)$. The results showed those who were taking alcohol were 11 times more likely to develop TB compared to those not taking alcohol $(\mathrm{OR}=11.16$; 95\%CI:6.36,19.62), alcohol was significantly associated with development of TB. The results showed that those who had never smoked had $83 \%$ not likely to develop TB compared to the past or currently smokers $(\mathrm{OR}=0.17 ; 95 \% \mathrm{CI}: 0.10,0.28)$, Smoking was significantly associated with development of $\mathrm{TB}(\mathrm{p}=<0.001)$. The results indicated that those cases who were not on IPT were twenty times more likely to develop TB compared to those who were not on IPT $(\mathrm{OR}=20.94 ; 95 \% \mathrm{CI} ; 11.55,37.97)$, IPT was significantly associated with development of TB $(p=<0.001)$. The results indicated that history of contact of TB was 10 times more likely to develop TB compared to those without the history of $\mathrm{TB}$ contact $(\mathrm{OR}=10.19 ; 95 \% \mathrm{CI}: 5.32,19.49)$, history of contact of TB was significantly associated with development of TB $(p=<0.001)$. ( As shown in table 2$)$.

\section{Discussion}

The study assessed the socio demographic risk factors for developing Tuberculosis after highly active anti retro viral treatment initiation the results indicated that several socio demographic factors influence the development of TB after HAART.

The finding of the study showed that males were mostly affected by TB, this is similar to the study done in Russia and Kenya which showed that males are affected more with TB 
than females [17-18]. Study done in Mombasa contradicts with this finding which showed that females were more affected with TB than males [19]. This can be attributed to social factors since men have more social contact thus expose to contagious diseases like TB.

Table 2. Clinical characteristics of study participants in factors affecting TB HIV co-infection in Bungoma County, 2015.

\begin{tabular}{|c|c|c|c|c|c|c|c|c|c|}
\hline & \multirow{2}{*}{ Cases $n=156(\%)$} & \multirow{2}{*}{ Controls $n=156$ (n) } & \multirow{2}{*}{$p$ value } & \multirow{2}{*}{ uOR } & \multicolumn{2}{|c|}{$95 \%$ CI } & \multirow{2}{*}{ AOR } & \multicolumn{2}{|l|}{$95 \%$ CI } \\
\hline & & & & & Lower & Upper & & Lower & Upper \\
\hline \multicolumn{10}{|c|}{ WHO stage } \\
\hline i\&ii & $31(20)$ & $124(79)$ & \multirow{2}{*}{$<.001$} & $1 \mathrm{REF}$ & & & & & \\
\hline iii\&iv & $125(80)$ & $32(21)$ & & 15.63 & 8.99 & 27.16 & 15.53 & 7.67 & 31.45 \\
\hline \multicolumn{10}{|c|}{ CD4 cell count } \\
\hline$<500$ & $150(96)$ & $105(67)$ & $<.001$ & 12.14 & 5.03 & 29.33 & 9.88 & 3.68 & 26.50 \\
\hline \multicolumn{10}{|c|}{ Body mass index } \\
\hline$<18.5$ & $108(69)$ & $35(22)$ & \multirow{3}{*}{0.212} & 6.32 & \multirow[t]{3}{*}{3.78} & \multirow[t]{3}{*}{10.58} & 7.24 & \multirow[t]{3}{*}{3.83} & \multirow[t]{3}{*}{13.66} \\
\hline $18.5+$ & $48(31)$ & $120(77)$ & & $1 \mathrm{REF}$ & & & 1 & & \\
\hline \multicolumn{5}{|c|}{ Interrupted ARV } & & & & & \\
\hline Yes & $88(56)$ & $19(12)$ & \multirow{2}{*}{$<.001$} & 5.572 & \multirow[t]{2}{*}{3.136} & \multirow[t]{2}{*}{9.9} & 2.72 & \multirow[t]{2}{*}{0.347} & \multirow[t]{2}{*}{21.308} \\
\hline No & $68(44)$ & $137(88)$ & & $1 \mathrm{REF}$ & & & 1 & & \\
\hline Yes & $99(63)$ & $21(13)$ & \multirow{2}{*}{$<.001$} & 11.165 & \multirow[t]{2}{*}{6.355} & 19.616 & 8.62 & 3.37 & 21.99 \\
\hline No & $57(37)$ & $134(86)$ & & $1 \mathrm{REF}$ & & & 1 & & \\
\hline Smoking & & & & & & & & & \\
\hline Never & $57(37)$ & $121(78)$ & $<001$ & 0.17 & 0.10 & 0.28 & 0.31 & 0.13 & 0.71 \\
\hline Smoker & $98(63)$ & $35(23)$ & $<.001$ & $1 \mathrm{REF}$ & & & 1 & & \\
\hline History & & & & & & & & & \\
\hline Yes & $8(5)$ & $2(1)$ & 0054 & 4.162 & 0.87 & 19.923 & & & \\
\hline No & $148(95)$ & 154 (99) & 0.034 & $1 \mathrm{REF}$ & & & & & \\
\hline Isonazid & e therapy & & & & & & & & \\
\hline Yes & $20(13)$ & $118(76)$ & $<001$ & $1 \mathrm{REF}$ & & & 1 & & \\
\hline No & $136(87)$ & $38(24)$ & $<.001$ & 20.937 & 11.546 & 37.966 & 35.29 & 13.81 & 90.20 \\
\hline History & tact & & & & & & & & \\
\hline Yes & $81(48)$ & $13(8)$ & 00 & 10.185 & 5.323 & 19.488 & 6.43 & 2.93 & 14.10 \\
\hline No & $75(52)$ & $143(92)$ & .001 & $1 \mathrm{REF}$ & & & 1 & & \\
\hline
\end{tabular}

The study showed that age was not associated with development of TB, this finding are similar to study done in Ethiopia which showed that age was not a risk factor for development of TB [20]. This finding contradicts with study done in Mombasa, Kenya and Gambia that showed that most of the patients affected were between the age of 25 and 49 $[17,18,21]$. This can be attributed to the fact that most of people affected by HIV are in the reproductive age group thus no difference between the TB co-infected and those not co-infected.

The study showed that marital status was a factor influencing TB, being divorce or widower was associated with development of TB among people living with HIV, this is consistent with study done in Gambia and Guinea Bissau $[11,22]$, which showed that patients who were divorced/widowed were at great risk of developing TB. This can be due to being married lead to positive psychological and social impacts [23].

The study results showed education level was not a factor associated with development of TB after adjusting for the odd ratio. This contradict with the finding in the study done in Ethiopia and India that showed that those no formal education were more likely to develop TB [24-25] this can be due to high level of patient who at least have primary level in the study population.

The study showed that income was not associated with development TB. This contradicts with the study done in 134 countries, Nairobi and Nakuru which showed that TB was associated with poverty [26-28]. This can be attributed to the fact that most of the study population was from area where Agriculture is done on large scale; most of the study participants were farmers.

The study assesses the clinical risk factors for developing Tuberculosis after highly active anti-retroviral treatment initiation the results indicated that several factors influence the development of TB after starting on HAART

The study showed that WHO clinical stage iii and iv was associated with development of TB which is similar to the results of a studies done in South Africa and Ethiopia [29-30] that showed that WHO clinical stage iii \& iv was associated with development of TB. This can be attributed to reactivation of latent $\mathrm{TB}$ due to reduced immunity.

The study results indicates that malnutrition was not associated with development of TB the result contradict with a study done in Uganda and South Africa [31-32] which showed that BMI below 18.5 was associated with development of TB. This can be attributed to the fact that most of HIV patients are put on food supplements and 
counseling which tend to improve their nutritional status.

The study results also indicates that past and current smoking was a factor associated with development of $\mathrm{TB}$, the results agrees with the study done in West Africa that showed that smoking was associated with development of TB [11], but it differs with the study done in Gambia [22] which showed that smoking was not associated with the development of TB. The association between smoking and TB has been studied in several systematic reviews [33-38]. Bates and colleagues, shows that relative risk of $\mathrm{TB}$ disease and $\mathrm{TB}$ death was more among the smokers [36]. This can be attributed to impaired clearance of mucosal secretion, reduced phagocytic ability of alveolar macrophages [39-40] and decrease in the immune response due to the nicotine [40].

The study also showed that alcohol was a factor influencing $\mathrm{TB}$ in patients living with HIV, this results is similar in meta analysis that recognize alcohol as a strong risk factor for TB disease [41]. A systematic review of 3 cohort and 18 case control studies concluded that the risk of TB was high in alcoholic. This can be attributed to alteration in the immune system.

Different studies have shown that Isonazid preventive therapy (IPT) reduces the risk of TB infection in PLWHIV [41-45]. Similarly, in this study, patients who were on IPT were at the lower risk of developing $\mathrm{TB}$ and being on isonazid was protecting against. The study agrees with the study done in Ethiopia with showed that being on IPT was not associated with TB co-infection [25]. This is attributed to the fact that Isonazid is used in treatment of latent TB thus reduced risk of reactivation of latent $\mathrm{TB}$.

The study showed that low CD4 was associated with the development of TB, this is similar to the results done in study done in Ethiopia and South Africa $[25,46]$ that showed that those with low CD4 were at a higher the risk of TB during $\mathrm{ART}$, this can be attributed to the factor of low immunity which predispose one to reactivation of latent $T B$.

The study showed that Asthma was not associated with development of TB this is consistency with study done in Gambia which showed that Asthma was not associated with TB [22] but contradicts with study done in West Africa which showed that asthma was protective against TB [47].

The study showed that those patients who had interrupted ART was associated with development of TB this can be due to the factor that when one stop taking the ART the immunity reduces and there is reactivation of latent TB.

\section{Conclusion and Recommendation}

Having poor clinical stage (WHO stage iii \& iv) and low CD4 cell count were found to be associated with development of Tuberculosis. All people living with HIV/AIDS should be screened for TB. But, in the presence of the risk factors mentioned in this study, intensified screening is highly recommended during follow up. In addition, increasing coverage of IPT is necessary to reduce the overall risk of TB among HIV. Adherence counseling is important in order to avoid ART treatment interruption.

\section{Conflict of Interest}

The authors declare that they have no competing interests.

\section{Authors' Contribution}

All authors participated by writing the study protocol, participated collecting data, data analysis, report writing, drafted the paper with subsequent revision and approved the final manuscript

\section{Acknowledgements}

Acknowledgement goes to Amref Health Africa, Nairobi for financially supporting the implementation various research steps.

\section{References}

[1] World Health Organization, Tuberculosis Fourth Edition, The Essentials, Edited By Dr Mario C. Raviglione, World Health Organization, Geneva Switzerland, 2010, http://www.who.int/ tb/features archive/the essentials/en/.

[2] World Health Organization, Promoting the Implementation of Collaborative TB/HIV Activities through Public-Private Mix and Partnerships Report of a WHO Consultation, World Health Organization, Geneva, Switzerland, 2008, http://whqlibdoc .who.int/hq/2008/WHO HTM TB 2008.408 eng.pdf.

[3] World Health Organization (2011) Global tuberculosis control report. WHO 2011, Geneva

[4] World Health Organization. Global Tuberculosis [Internet]. Vol. 312, Jama. GENEVA; 2013. Available from: http://www.ncbi.nlm.nih.gov/pubmed/25188638

[5] Department of Tuberculosis. National Tuberculosis, Leprosy and Lung Disease Program; annual report,2015 [Internet]. NAIROBI; 2015. Annual Report 2015 .pdf

[6] Habib AG (2009) A clinical and epidemiologic update on the interaction between tuberculosis and human immunodeficiency virus infection in adults. Annals of African Medicine 8(3): 147-155.

[7] Preliminary report for the U.S. Office of the Global AIDS Coordinator (2004) Integrating HIV/AIDS \& TB Efforts. The Challenge for the President's AIDS Initiative. Network Public Health. February, 2004.

[8] Boccia D, James H, Bianca LDS, Katherine F, Chaap AbS, et al. (2011) The Association between Household Socioeconomic Position and Prevalent Tuberculosis in Zambia: A Case-Control Study. PLoS ONE 6(6): e20824.doi:10.1371/ journal.pone.0020824.

[9] Baalwa Joshua, Mayanja-Kizza H, Kamya MR, John L, Kambugu A, et al (2008) Worsening and unmasking of tuberculosis in HIV-1infected patients after initiating highly active anti-retroviral therapy in Uganda. African Health Sci 8(3): 190-195 
[10] Taha M, Derbew A., Tessema F, Assegid S, Duchateau L, et al (2001) Risk factors of active tuberculosis in people living with HIV/AIDS in southwest Ethiopia: a case control study. Ethiop J Health Sci 21(2): 131-139.

[11] Lienhardt C, Fielding K, Sillah JS, Bah B, Gustafson P, et al. (2005) Investigation of the risk factors for tuberculosis: a case-control study in three countries in West Africa. Int $\mathrm{J}$ of Epidemiol 34: 914-923.

[12] Perez A, Brown HS, Restrepo BI (2006) Association between tuberculosis and diabetes in the Mexican border and non-border regions of Texas. Am J Trop Med Hyg 74(4): 604-611.

[13] World Health Organization (2011) Guidelines for intensified tuberculosis case finding and isoniazid preventive therapy for people living with HIV in resource constrained settings. WHO, Geneva, 2011.

[14] Komati S, Shaw PA, Stubbs N, Mathibedi MJ, Malan L, et al. (2010) Tuberculosis Risk Factors and Mortality for HIV Infected Persons Receiving Antiretroviral Therapy in South Africa. AIDS 24(12):1849-1855. doi:10.1097/QAD.0b013e32833a2507.

[15] World Health Organization (2010) Global tuberculosis control: a short update to the 2012 report, Geneva. WHO 2010 (WHO/HTM/TB/2010.7).

[16] KNBS report, Kenya National Bureau of statistics, 2009

[17] Kipruto H, Mung'atu J, Ogila K, Adem A, Mwalili S, Masini E and Kibuchi E (2015) The epidemiology of tuberculosis in Kenya, a high TB/HIV burden country (2000-2013) International Journal of Public Health and Epidemiology Research Vol. 1(1), pp. 002-013, October, 2015.

[18] Fleming MF, Krupitsky E, Tsoy M, Zoartau E, Brazhenko N, et al. (2006) Alcohol and drug use disorders, HIV status and drug resistance in a sample of Russian Patients. International Journal of Tuberculosis and Lung Disease.

[19] Young F, Wotton CJ, Critchley JA, Unwin NC, Goldacre MJ (2012). Increased risk of tuberculosis disease in people with diabetes mellitus: record-linkage study in a UK population. $J$ Epidemiol Community Health. 2012;66(6):519-23.

[20] Heitham Awadalla, Fateh El-Samani , Mohammed A. Soghaier 3, and Mahgoub Makki Risk Factors Associated with the Development of Tuberculosis Among HIVInfected Patients in Khartoum in 2010 AIMS Public

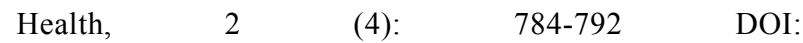
10.3934/publichealth.2015.4.7842015.

[21] Lienhardt C, Fielding K, Sillah J, Tunkara A, Donkor S, Manneh K, et al (2003). Risk factors for tuberculosis infection in Sub-Saharan Africa. Am J Respir Crit Care Med. 2003;168(4):448-55.

[22] Hill. P. C, D. Jackson-Sillah, S. A. Donkor, J. Otu, R. A. Adegbola, and C. Lienhardt, "Risk factors for pulmonary tuberculosis: a AIDS Research and Treatment 7 clinic-based case control study in The Gambia," BMC Public Health, vol. 6, no. 156, 2006.

[23] Gallagher. M, "Marriage and Public Health: Institute for American Values The Case for Marriage," 2001, USA, http://www .americanvalues.org/.
[24] Dheeraj Gupta, Kshaunish Das, Balamughesh T, Ashutosh N. Aggarwal and Surinder. K. Jindal (2003) role of socioeconomic factors in tuberculosis prevalence, Indian $J$ Tuberc 2004, 51: 27-31.

[25] Hatoluf Melkamu, Berhanu Seyoum, and Yadeta Dessie (2013) Determinants of Tuberculosis Infection among Adult HIV Positives Attending Clinical Care in Western Ethiopia A Case-Control Study Hindawi Publishing Corporation AIDS Research and Treatment Volume 2013, Article ID 279876, 7 http://dx.doi.org/10.1155/2013/279876.

[26] Dye. C, K. Lonnroth, E. Jaramillo, B. G. Williams and M. Raviglione, "Trends in Tuberculosis Incidence and Their Determinants in 134 Countries," Bulletin of World Health Organization, Vol. 87, No. 9, 2009, pp. 683-691. doi:10.2471/BLT.08.058453.

[27] Perpetual Wangui Ndungu1, Gunturu Revathi, Samuel Kariuki, Zipporah Ng'ang'a Risk Factors in the Transmission of Tuberculosis in Nairobi: A Descriptive Epidemiological Study Advances in Microbiology, 2013, 3, 160-165

[28] Amwayi A. S, Kikuvi GM, Muchiri EM. Modifiable factors associated with active pulmonary tuberculosis in a Kenyan prison. East Africa medical jounal 87(2):43-8. 2010.

[29] Komati S, Shaw PA, Stubbs N, Mathibedi MJ, Malan L, et al. (2010) Tuberculosis Risk Factors and Mortality for HIV Infected Persons Receiving Antiretroviral Therapy in South Africa. AIDS 24(12):1849-1855. doi:10.1097/ QAD.0b013e32833a2507.

[30] Kibret KT, Yalew AW, Belaineh BG, Asres MM (2013) Determinant Factors Associated with Occurrence of Tuberculosis among Adult People Living with HIV after Antiretroviral Treatment Initiation in Addis Ababa, Ethiopia: A Case Control Study. PLoS ONE 8(5): e64488. doi:10.1371/journal.pone.0064488.

[31] Mupere. E, S. Zalwango, A. Chiunda, A. Okwera, R. Mugerwa, and C. Whalen, "Body composition among HIVseropositive and HIV-seronegative adult patients with pulmonary tuberculosis in Uganda," Annals of Epidemiology, vol. 20 , no. 3, pp. 210-216, 2010.

[32] Hatoluf Melkamu, Berhanu Seyoum, and Yadeta Dessie (2013) Determinants of Tuberculosis Infection among Adult HIV Positives Attending Clinical Care in Western Ethiopia A Case-Control Study Hindawi Publishing Corporation AIDS Research and Treatment Volume 2013, Article ID 279876, http://dx.doi.org/10.1155/2013/279876

[33] Maurya. V, V. K. Vijayan, and A. Shah, "Smoking and tuberculosis: an association overlooked," International Journal of Tuberculosis and Lung Disease, vol. 6, no. 11, pp. 942-951, 2002.

[34] Arcavi. L, andN. L. Benowitz, "Cigarette smoking and infection," Archives of Internal Medicine, vol. 164, no. 20, pp. 2206-2216, 2004.

[35] Yanbaeva. D,G, M. A. Dentener, E. C. Creutzberg, G. Wesseling, and E. F. M. Wouters, "Systemic effects of smoking," Chest, vol. 131, no. 5, pp. 1557-1566, 2007.

[36] Bates. M. N, A. Khalakdina, M. Pai, L. Chang, F. Lessa, and K. R. Smith, "Risk of tuberculosis from exposure to tobacco smoke: a systematic review and meta-analysis," Archives of Internal Medicine, vol. 167, no. 4, pp. 335-342, 2007. 
[37] Slama. K, C. Y. Chiang, D. A. Enarson et al., "Tobacco and tuberculosis: a qualitative systematic review and metaanalysis," International Journal of Tuberculosis and Lung Disease, vol. 11, no. 10, pp. 1049-1061, 2007.

[38] Pai. M, A. Mohan, K. Dheda et al., "Lethal interaction: the colliding epidemics of tobacco and tuberculosis," Expert Review of Anti-Infective Therapy, vol. 5, no. 3, pp. 385-391, 2007.

[39] Sopori. M, "Effects of cigarette smoke on the immune system," Nature Reviews Immunology, vol. 2, no. 5, pp. 372$377,2002$.

[40] Wang. H, M. Yu, M. Ochani et al., "Nicotinic acetylcholine receptor $\alpha 7$ subunit is an essential regulator of inflammation," Nature, vol. 421, no. 6921, pp. 384-388, 2003.

[41] L“onnroth. K. L, B. G. Williams, S. Stadlin, E. Jaramillo, and C. Dye, "Alcohol use as a risk factor for tuberculosis-a systematic review," BMC Public Health, vol. 8, article 289, 2008 .

[42] Akolo C, Adetifa I, Shepperd S, Volmink J (2010) Treatment of latent tuberculosis infection in HIV infected persons. Cochrane Database Syst Rev (1): CD000171.
[43] Golub JE, Saraceni V, Cavalcante SC, Pacheco AG, Moulton LH, et al. (2007) The impact of antiretroviral therapy and isoniazid preventive therapy on tuberculosis incidence in HIVinfected patients in Rio de Janeiro, Brazil. AIDS 21(11): 1441-8.

[44] Lawn SD, Wood R, Cock KMD, Kranzer K, Lewi JJ, et al. (2010) Antiretroviral and isoniazid preventive therapy in the prevention of HIV-associated tuberculosis in settings with limited health-care resources. Lancet Infect Dis 10: 489-98.

[45] Churchyard GJ, Fielding K, Charalambous S, Day JH, Corbett EL, et al. (2003) Eficacy of secondary isoniazid preventive therapy among HIV-infected Southern Africans: time to change policy? AIDS 17: 2063-2070.

[46] Lawn. S and L. G. Bekker, (2009) "Co pathogenesis of Tuberculosis and HIV," in Tuberculosis: A Comprehensive Clinical Reference, pp. 96-106, Elsevier, 2009.

[47] Cheru Tesema Takele Tadesse Mulat Gebrehiwot Azanaw Tsegaw Fitsum Weldegebrea 14 Environmental and hostrelated determinants of tuberculosis in Metema district, northWest Ethiopia Drug, Healthcare and Patient Safety 2015: 7 87-95. 